20

\title{
Применение терагерцовой спектроскопии для in vivo исследования динамики развития лимфедемы*
}

\author{
(C) Ю.В. Кистенев ${ }^{1,2}$, В.В. Николаев ${ }^{1,3}$, О.С. Курочкина ${ }^{4}$, А.В. Борисов ${ }^{1,2}$, Е.А. Сандыкова ${ }^{1,2}$, \\ Н.А. Кривова ${ }^{1}$, Д.К. Тучина ${ }^{1,5}$, П.А. Тимошина ${ }^{1,5}$ \\ ${ }^{1}$ Национальный исследовательский Томский государственный университет, \\ 634050 Томск, Россия \\ ${ }^{2}$ Сибирский государственный медицинский университет, \\ 634050 Томск, Россия \\ ${ }^{3}$ Институт физики прочности и материаловедения СО РАН, \\ 634055 Томск, Россия \\ ${ }^{4}$ АНО „НИИ микрохирургии“, \\ 634063 Томск, Россия \\ ${ }^{5}$ Саратовский национальный исследовательский государственный университет им. Н.Г. Чернышевского, \\ 410012 Саратов, Россия \\ e-mail: yuk@iao.ru
}

Поступила в редакцию 05.12.2018 г.

В окончательной редакции 25.12.2018 г.

Принята к публикации 31.01. 2019 г.

\begin{abstract}
Представлена лабораторная модель развития лимфедемы, реализованная путем резекции лимфососудов в конечности крыс. In vivo анализ развития лимфедемы (период наблюдения - 4 недели) проведен методом отражательной терагерцовой спектроскопии с использованием призмы Дове. Применен режим падения электромагнитной волны с $s$-поляризацией на границу „призма-биоткань“ под углом, близким к углу Брюстера. Выявлено значимое изменение спектральных характеристик ткани конечности животных на 21-28-й дни развития лимфедемы. Построена прогностическая модель диагностики данного заболевания на основе изменения профилей кривой поглощения ткани в области $0.4-1.1 \mathrm{THz}$ с использованием метода главных компонент и метода опорных векторов.
\end{abstract}

DOI: $10.21883 /$ OS.2019.05.47659.8-19

\section{Введение}

Лимфедема - хроническое прогрессирующее заболевание лимфатической системы, вызванное аномальным накоплением тканевой жидкости с высоким содержанием белка, что приводит к разрастанию волокнистой соединительной ткани, гипертрофии жировой ткани, воспалению $[1,2]$. Лимфедема ограничивает подвижность больного, вызывает сильный дискомфорт [3-5]. Ее ранняя диагностика помогает не только правильно подобрать лечение, но и предотвратить дальнейшее развитие заболевания [6].

Методы диагностики лимфатической системы становятся все более востребованными в связи с растущим интересом к проблемам молекулярной лимфологии. Лимфангиогенез является ключевым в таких процессах, как клеточная пролиферация, управляемая миграция клеток, дифференциация и связь между ними, регенерация тканей и заживление ран [7]. Лимфатические

\footnotetext{
* The 22nd Annual Conference Saratov Fall Meeting 2018 (SFM'18): VI International Symposium „Optics and Biophotonics“ and XXII International School for Junior Scientists and Students on Optics, Laser Physics \& Biophotonics, September 24-29, 2018, Saratov, Russia. https://www.sgu.ru/structure/fiz/saratov-fall-meeting/previousconferences/sara
}

сосуды играют центральную роль в метастазировании онкологических клеток, отторжении органов.

Распространены методы диагностики лимфедемы, основанные на регистрации изменения геометрических параметров конечности, такие как измерение окружности (используют не только обычные приборы для измерения линейных размеров, но оптические методы) или ее объема, например, путем оценки вытесненной жидкости в резервуаре, куда помещают конечность. Однако такие методы не являются точными и согласованными [8].

Прерывистая воздушная компрессия - терапевтический метод уменьшения лимфатического отека, который также позволяет изучить механические (упругие) свойства подкожной ткани и провести диагностику заболевания, определить эффективность лечения [9].

Исследование упругих свойств ткани возможно с использованием оптической когерентной эластографии. Подход сочетает использование интерференционного метода исследования пространственного распределения неоднородностей в ткани и возбуждение упругих волн ультразвуковым источником. Оптическая когерентная эластография неинвазивна и обеспечивает количественную оценку упругих свойств ткани в клинических условиях $[10,11]$. Однако метод характеризуется невысоким отношением сигнал/шум, существуют сложности анали- 
за сигналов, связанные с неоднозначностью восстановления фазы.

Диагностика лимфатических отеков конечностей методом лимфографии основана на использовании различных контрастирующих агентов, которые вводятся в лимфоток. Инфракрасная лимфография с использованием индоцианина зеленого (indocyanine green) позволяет визуализировать даже небольшие лимфатические сосуды [12]. Неудобство метода связано с необходимостью введения контрастирующих агентов в биоткань.

Перспективным для медицинских приложений является молекулярная спектроскопия и визуализация биотканей в терагерцовой $(\mathrm{THz})$ области спектра [13]. Это связано с тем, что в данную спектральную область попадают линии поглощения, обусловленные вращением и низкочастотными колебательными модами биологических макромолекул, деформациями водородных связей [14-17]. ТГц спектроскопия позволяет исследовать взаимодействие воды и водородных структур с другими молекулами, присутствующими в биологических системах, таких как аминокислоты, пептиды, ДНК, белки [16].

Пространственное сканирование исследуемого образца при помощи $\mathrm{THz}$ спектроскопии с временным разрешением (time domain spectroscopy, TDS) позволяет изучить внутреннюю структуру и химический состав биоткани, даже если спектральные линии поглощения ее молекулярных компонент не разрешены $[18,19]$.

TDS THz спектроскопия может быть использована в режиме нарушенного полного внутреннего отражения (НПВО) для исследования оптических свойств кожи in vivo. В работе [20] с использованием НПВО исследованы спектральные зависимости оптических характеристик кожи различных частей тела здоровых добровольцев в диапазоне $0.2-1.5 \mathrm{THz}$. Показано, что в данном диапазоне коэффициент поглощения монотонно растет до значений $1-2 \cdot 10^{2} \mathrm{~cm}^{-1}$, а показатель преломления уменьшается до значений около 1.5 на частоте $1.5 \mathrm{THz}$.

Целью настоящей работы является исследование возможности терагерцовой спектроскопии для контроля in vivo процесса развития лимфедемы на модели мелких животных.

\section{Материалы и методы}

\section{Протокол экспериментальной модели развития лимфедемы}

Для создания модели лимфедемы использованы самцы крыс Wistar (питомник Института фармакологии СО РАН) в возрасте 8-10 недель (масса 200-250 g). Протокол исследования был одобрен Комитетом по биоэтике НИ ТГУ (выписка из протокола заседания № 1).

Крысы (12 голов) содержались в изолированном вентилируемом помещении вивария Института биологии и биофизики Томского государственного университета. Все животные были промаркированы и содержались в

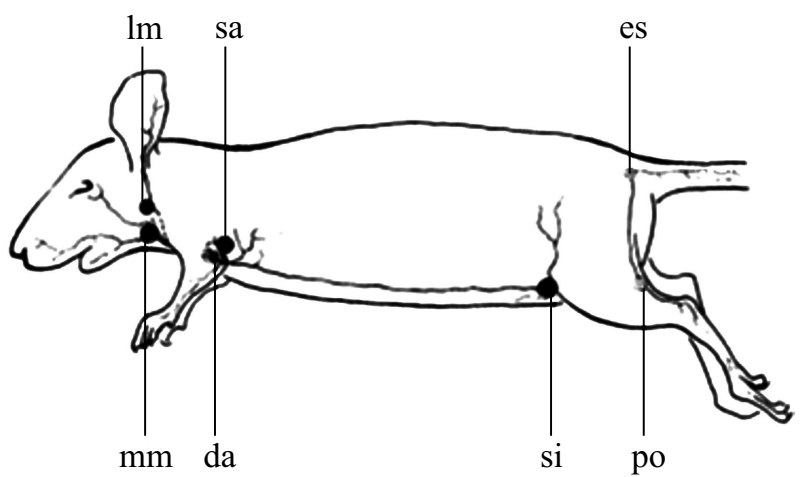

Рис. 1. Лимфатические узлы и сосуды тела крысы: $\mathrm{mm}-$ медиальный нижнечелюстной узел; $1 \mathrm{~m}$ - латеральный нижнечелюстной узел; da - глубокие подмышечные узлы; sa поверхностные подмышечные узлы; si - узел, расположенный под подвздошной костью; ро - подколенный узел; es наружный крестцовый узел.

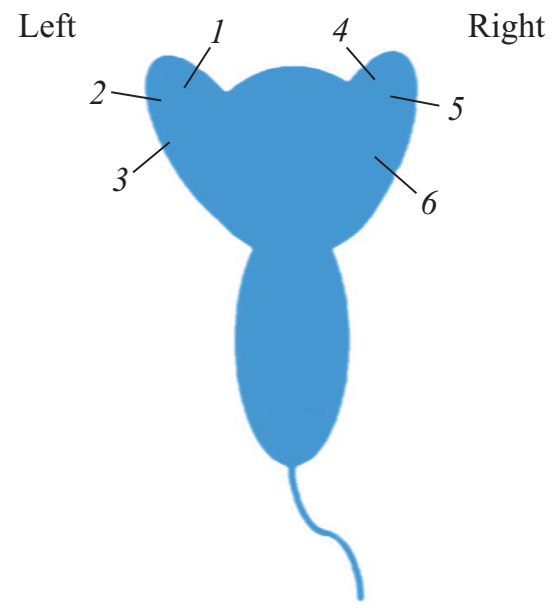

Рис. 2. Схема маркировки крыс путем надрезов на ушах.

течение 7 суток на карантине, при свободном доступе к воде и пище (стандартный рацион для крыс). В помещении поддерживалась температура $20 \pm 2{ }^{\circ} \mathrm{C}$, влажность воздуха $60 \%, 12 \mathrm{~h}$ свет $/ 12 \mathrm{~h}$ темнота.

В основу модели развития лимфедемы положена методика, описанная в [21]. Методика основана на резекции подколенного узла на одной лапе животного, вторая лапа использовалась для контроля. Операция осуществлялась по следующему протоколу.

Предварительно проводилась анестезия (золетил внутримышечно). Расчет дозы препаратов выполнялся в соответствии с массой животного. После обработки операционного поля водным раствором хлоргексидина осуществлялось введение $0.1 \mathrm{ml} \quad 0.1 \%$ раствора метиленового синего подкожно в тыльную поверхность задней лапы. Затем лапу массировали в течение $1-2 \mathrm{~min}$. В результате контраст из подкожно-жировой клетчатки попадал в глубокие лимфатические коллекторы и доходил до подколенных лимфатических узлов (рис. 1). 
После окрашивания глубоких лимфатических коллекторов и подколенных лимфатических узлов выполняли разрез кожи до $1.5 \mathrm{~cm}$ в подколенной области. При ревизии выделяли окрашенные подколенные лимфатические узлы, к которым шли глубокие лимфатические коллекторы задней конечности.

Далее выполняли лимфодиссекцию подколенного лимфатического узла (Inn. popliteus), нарушая, таким образом, отток лимфы по глубокой лимфатической системе задней конечности. Затем вдоль сосудисто-нервного пучка выделяли подкожно-жировую клетчатку и рассекали ткани, сохраняя сосудисто-нервный пучок интактным. Денервацию, как в оригинальной методике [21], не проводили. После выполнения лимфодиссекции проводили контроль гемостаза, послойно накладывали швы на мягкие ткани (ПГА 4/0, фторэкс 4/0).

У каждой крысы была сделана маркировка в виде надреза на ушах согласно рис. 2. Первые 5 суток после операции крысы содержались в индивидуальных клетках. Раны ежедневно обрабатывали хлоргексидином и метилурацилом, присыпали метронидазолом. Все раны заживали первичным натяжением, потерь после операции не было.

\section{Протокол набора экспериментальных данных}

Были выбраны следующие точки наблюдения: 7-е, 14-е, 21-е, 28-е сутки после операции. В ходе измерений было проанализировано 12 крыс по схеме, показанной в табл. 1.

Для анализа оптических характеристик биологических тканей мелких животных использовался TDS THz спектрометр T-spec фирмы EKSPLA, оптическая схема которого приведена на рис. 3 [22].

Для проведения измерений in vivo использовалась призма Дове в режиме отражения, изготовленная из фторопласта. Выбор фторопласта для изготовления призмы обусловлен его нулевой гигроскопичностью (в отличие,

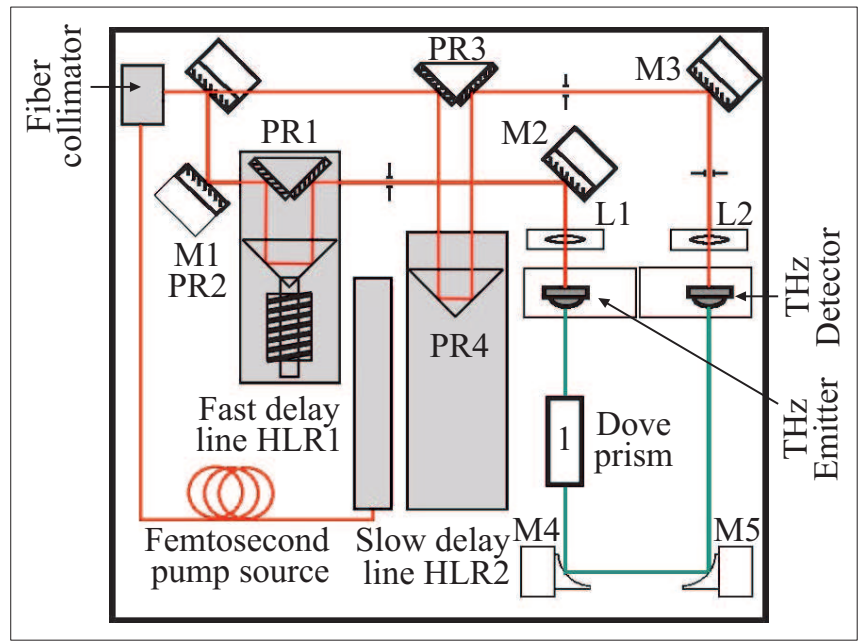

Pис. 3. Оптическая схема TDS THz спектрометра T-spec: M1-M5 - зеркала, L1-L2 - линзы, PR1-PR4 - призмы.
Таблица 1. График проведения измерений

\begin{tabular}{c|c|c}
\hline $\begin{array}{c}\text { Сутки } \\
\text { после } \\
\text { операции }\end{array}$ & $\begin{array}{c}\text { THz } \\
\text { спектроскопия }\end{array}$ & $\begin{array}{c}\text { Выход } \\
\text { из эксперимента }\end{array}$ \\
\hline 7 & 12 крыс & 3 крысы \\
14 & 9 крыс & 3 крысы \\
21 & 6 крыс & 2 крысы \\
28 & 4 крысы & 4 крысы
\end{tabular}
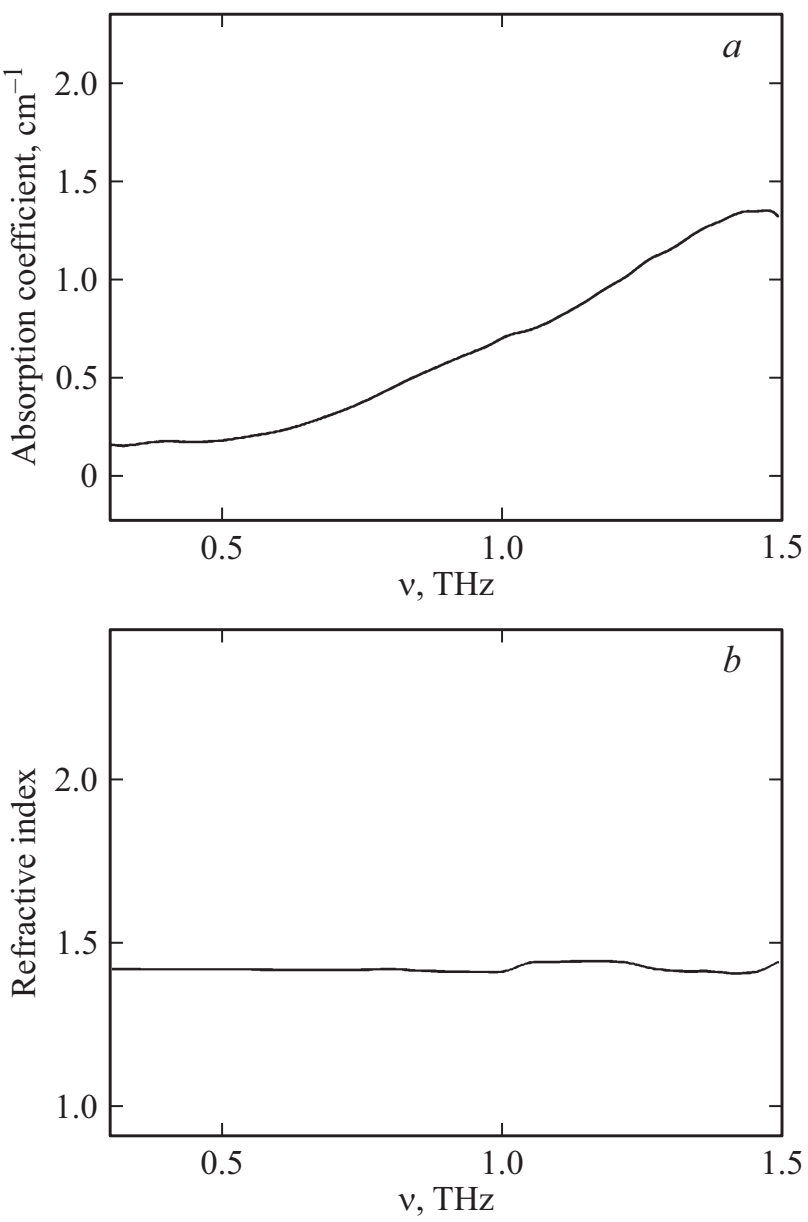

Рис. 4. Зависимость коэффициента поглощения $(a)$ и показателя преломления $(b)$ фторопласта.

например, от кремния), слабым поглощением (рис. 4, $a$ ) и практически постоянным значением показателя преломления в $\mathrm{THz}$ области спектра (рис. 4,b). Измерения данных зависимостей были проведены на образце толщиной $18 \mathrm{~mm}$. Использовался следующий алгоритм оценки зависимостей коэффициента поглощения и показателя преломления. В основе алгоритма лежит сравнение двух сигналов: $E_{\text {ref }}-$ опорного сигнала на приемнике на частоте $\omega$ (в отсутствие исследуемого образца) и аналогичного сигнала при наличии образца $E_{s a m p}$ на этой же частоте. Измеренная экспериментально переда- 
$a$
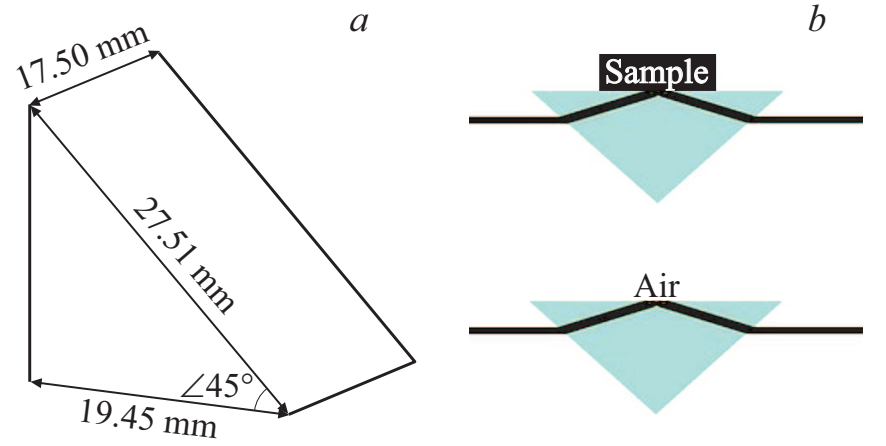

Рис. 5. Размеры призмы $(a)$ и схема эксперимента $(b)$.

точная функция образца определялась выражением

$$
H_{e x}=\frac{E_{\text {samp }}}{E_{\text {ref }}} .
$$

Для учета возможного переотражения на границах образца на основе измеренной зависимости $H_{e x}$ находилась передаточная функция $H_{\text {theor }}$ :

$$
\begin{aligned}
H_{\text {theor }}= & \sum_{k} 4 \frac{n_{\text {air }} n_{\text {samp }}}{\left(n_{\text {air }}+n_{\text {samp }}\right)^{2}}\left(\frac{n_{\text {air }}-n_{\text {samp }}}{n_{\text {air }}+n_{\text {samp }}}\right)^{2} \\
& \times \exp \left(-\frac{i \omega\left((2 k-1) n_{\text {samp }}-n_{\text {air }}\right) l}{c}\right),
\end{aligned}
$$

наилучшим образом соответствующая экспериментальной передаточной функции $H_{e x}$. Здесь $n_{\text {air }}, n_{\text {samp }}-$ комплексные показатели преломления воздуха и образца соответственно, $l$ - толщина образца, $c$ - скорость света, $k$ - целочисленный параметр, характеризующий эффект Фабри-Перо. В качестве меры близости указанных функций использовался функционал невязки $\operatorname{Err}$ в виде:

$$
\operatorname{Err}=\sum_{\omega}(|M(\omega)|+A|\omega|)
$$

где

$$
\begin{gathered}
M(\omega)=\left|H_{\text {theor }}\right|-\left|H_{e x}\right|, \\
A(\omega)=\text { phase }\left(H_{\text {theor }}\right)-\text { phase }\left(H_{e x}\right) .
\end{gathered}
$$

Решение обратной задачи эквивалентно минимизации функционала $E r r$ по показателю преломления $n_{s a m p}$ и параметру $k$. При решении задачи минимизации выбиралось следующее начальное значение $k$ :

$$
k=I N T\left\{-\frac{1}{l} \frac{c}{\omega} \log \frac{\left|E_{\text {samp, } \max }\right|}{\left|E_{\text {ref, } \max }\right|}\right\},
$$

где $\left|E_{s a m p, \max }\right|,\left|E_{r e f, \max }\right|-$ максимальные значения соответствующих сигналов, INT обозначает целую часть числа.

Призма с размерами, указанными на рис. 5, $a$, размещалась на пути пучка $\mathrm{THz}$ излучения в области 1 спектрометра (рис. 3). Измерения спектральных характеристик ткани проводились следующим образом.
Лапа находящейся под наркозом крысы размещалась на призме, проводилась запись спектра интенсивности сигнала. Для улучшения отношения сигнал/шум спектр усреднялся по 128 интервалам времени. Описанную процедуру повторяли для второй (здоровой) лапы крысы.

Согласно оптической схеме прибора, пучок ТГц излучения падает на боковую грань призмы Дове под углом, близким к $\pi / 4$ (рис. 5,b). При этом с учетом соотношения показателей преломления фторопласта (рис. $4, b)$ и воздуха угол падения на верхнюю грань призмы при отсутствии на ней образцов ткани оказывается больше предельного, т.е. реализуется условие полного внутреннего отражения. Однако коэффициент преломления биоткани в терагерцовой области спектра практически всегда превышает таковой для фторопласта. Например, зарегистрированный в работе [20] показатель преломления кожи человека менялся в пределах $1.5-2$ в диапазоне $0.2-1.5 \mathrm{THz}$. Таким образом, призма из фторопласта при исследовании биологических тканей не позволяет реализовать режим НПВО.

С учетом этого мы использовали в определенном смысле аналогичный НПВО режим отражения электромагнитной волны с $s$-поляризацией, перпендикулярной по отношению к плоскости падения, при ее падении на границу „призма-биоткань“ под углом, близким к углу Брюстера. Отражение волны с $s$-поляризацией описывается известной формулой Френеля [23]:

$$
r_{s}=\frac{\cos (\alpha)-\sqrt{\tilde{n}_{21}^{2}-\sin ^{2}(\alpha)}}{\cos (\alpha)+\sqrt{\tilde{n}_{21}^{2}-\sin ^{2}(\alpha)}}
$$

где $r_{s}$ - комплексный коэффициент отражения для $s$-поляризованного света, $\alpha$ - угол падения света на образец; $\tilde{n}_{21}=\tilde{n}_{2} / n_{1}-$ относительный показатель преломления, $n_{1}$ - показатель преломления призмы, $\tilde{n}_{2}=n_{2}+i \chi_{2}-$ комплексный показатель преломления биоткани.

Аналитическое исследование соотношения (1) возможно только для частных случаев, поэтому было проведено численное моделирование отражения электромагнитной волны с $s$-поляризацией на границе „призмабиоткань“" на основе (1). В расчетах были использованы модельные зависимости показателя преломления и коэффициента поглощения ткани (рис. 6), близкие к экспериментально зарегистрированным в [20].

На рис. 7 показан расчет логарифма квадрата модуля коэффициента $r_{s}$ при падении $s$-поляризованной электромагнитной волны на границу „призма-биоткань“ под углом, близким к углу Брюстера. В этих расчетах использовалась частотная зависимость показателя преломления, соответствующая рис. 6, а коэффициент поглощения считался независящим от частоты.

Видно, что частотная зависимость квадрата модуля $r_{s}$ отсутствует при вариации коэффициента поглощения в пределах 50-200 $\mathrm{cm}^{-1}$. Следовательно, в данном случае частотная зависимость показателя преломления 
биоткани не влияет на модуль коэффициента отражения на границе „призма-биоткань“. Отметим, что данный интервал как раз соответствует характеристикам реальной биоткани [20]. Кроме того, в указанных пределах зависимость квадрата модуля $r_{s}$ от величины коэффициента поглощения линейна в логарифмическом масштабе, т. е. данная зависимость подобна закону Бугера.

Таким образом, предложенный в работе режим отражения на границе „призма-биоткань“, позволяет исследовать абсорбционные характеристики биоткани.

\section{Методы анализа экспериментальных данных}

Содержательный анализ экспериментальных данных осуществлялся на основе совместного использования метода главных компонент и метода опорных векторов $[24,25]$.

Метод главных компонент позволяет выделить информативные признаки в исходных данных и, тем самым, исключить неинформативную часть данных из анализа. Метод опорных векторов является одним из наиболее эффективных методов бинарной классификации с обучением, часто используется при анализе медицинских данных [26]. Данный вид классификации использует этап обучения алгоритма на части экспериментальных данных, оставшаяся часть обычно используется для оценки эффективности классификатора.

\section{Результаты}

На рис. 8 для каждой временной контрольной точки протокола измерений представлены усредненные спектры поглощения ткани лап, на которых проводилась операция по удалению лимфоузла, и ткани здоровых

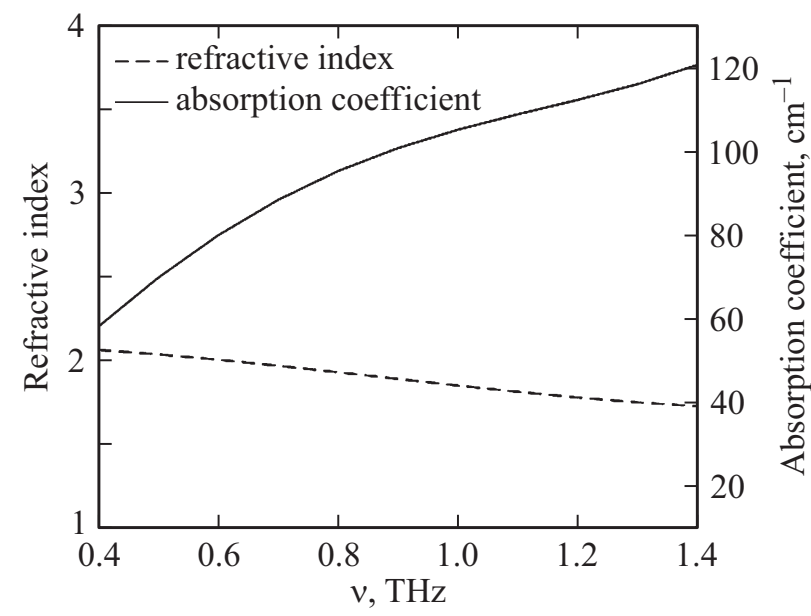

Рис. 6. Модельные зависимости показателя преломления и коэффициента поглощения ткани в области $0.2-1.5 \mathrm{THz}$.

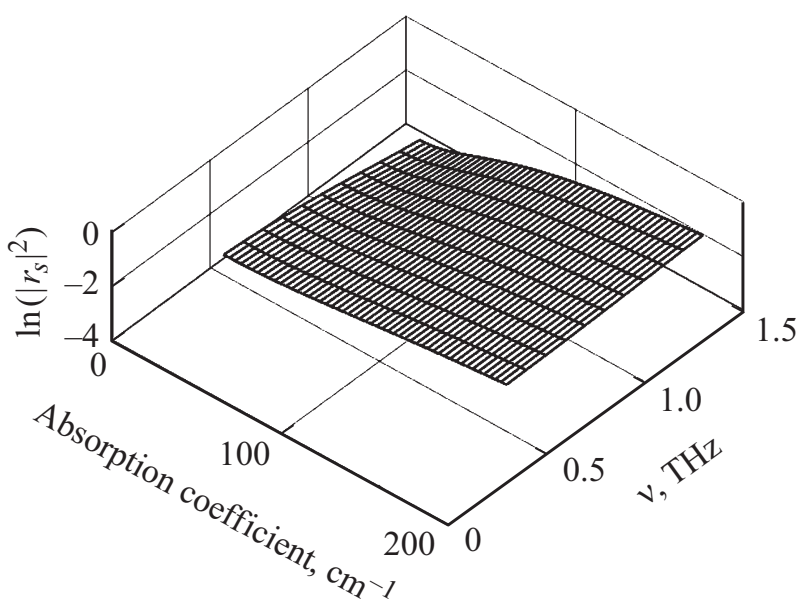

Рис. 7. Модельная спектральная зависимость логарифма квадрата модуля коэффициента $r_{s}$ при отражении s-поляризованной электромагнитной волны от верхней грани призмы Дове из фторопласта с размещенной на ней тканью. Угол падения волны на границу „призма-биоткань“ равен углу Брюстера на частоте $0.9 \mathrm{THz}$.

лап. Видно, что для здоровых лап значимых различий не наблюдалось. Для прооперированных лап на 3-4 неделях эксперимента появляются существенные изменения спектральных характеристик ткани в спектральной области $0.4-1.1 \mathrm{THz}$.

Для автоматического выявления информативных спектральных областей был использован метод главных компонент. Редуцированные спектры поглощения ткани прооперированных и здоровых лап представлены на рис. 9 в виде их проекции на гиперплоскость 1-й, 5й и 6-й главных компонент. Видно хорошее разделение между группами. Разное количество точек обусловлено тем, что часть животных еженедельно выводилась из эксперимента.

На основе выявленных информативных спектральных областей был построен классификатор с использованием метода опорных векторов с ядром в виде радиальной базисной функции (Rbf):

$$
K(x, y)=\exp \left(-\frac{\langle(x-y),(x-y)\rangle}{2 \sigma^{2}}\right) .
$$

Разделение исходных данных для обучения и тестирования классификатора проводилось случайным образом многократно (500 раз). В процессе обучения алгоритма классификации на полученном наборе данных было найдено оптимальное значение параметра ядра: $\sigma=0.633$. Результаты тестирования точности классификатора в терминах специфичности и чувствительности представлены в табл. 2.

\section{Заключение}

В работе исследована лабораторная модель лимфедемы, реализованная путем резекции лимфососудов в 
Таблица 2. Оценка специфичности и чувствительности классификатора

\begin{tabular}{c|c|c|c|c}
\hline \multirow{2}{*}{$\begin{array}{c}\text { Бинарная } \\
\text { классификация }\end{array}$} & $\begin{array}{c}|c| \\
\text { Среднее } \\
\text { значение }\end{array}$ & $\begin{array}{c}\text { Среднеквадратичное } \\
\text { отклонение }\end{array}$ & $\begin{array}{c}\text { Среднее } \\
\text { значение }\end{array}$ & $\begin{array}{c}\text { Среднеквадратичное } \\
\text { отклонение }\end{array}$ \\
\hline $\begin{array}{c}\text { Прооперированные } \\
\text { лапы /здоровые лапы }\end{array}$ & 0.7930 & 0.2097 & 0.8755 & 0.1961
\end{tabular}

нижней конечности крыс. In vivo анализ развития лимфедемы (период наблюдения - 4 недели) проведен с использованием отражательной терагерцовой спектроскопии. Была использована призма Дове в режиме, соответствующем падению $s$-поляризованной электромагнитной волны на границу „призма-биоткань“ под углом Брюстера.

Выявлено заметное изменение спектральных характеристик ткани прооперированных лап лабораторных животных на 21-28-й дни развития лимфедемы по сравнению со здоровыми лапами. Построена прогно-
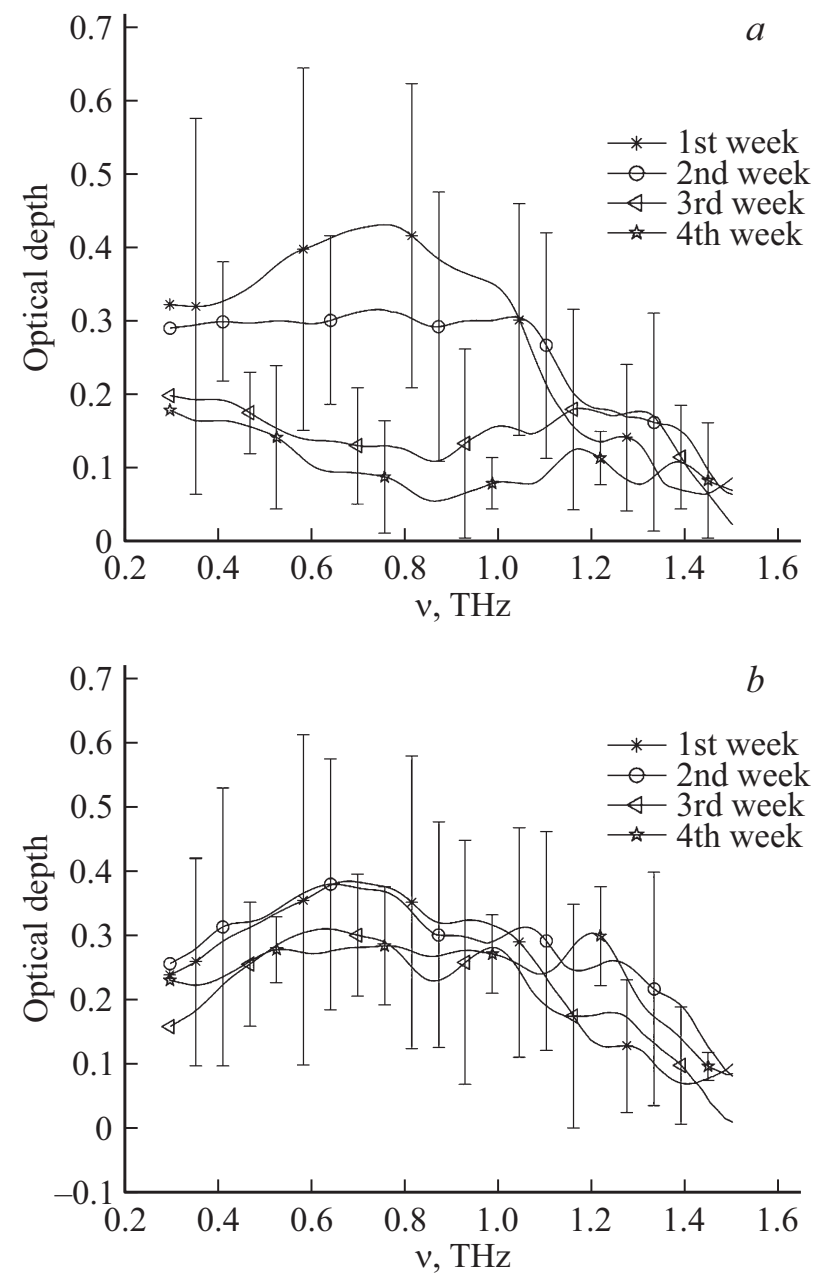

Рис. 8. Усредненные спектры поглощения лап, на которых проводилась операция по удалению лимфоузла $(a)$ и здоровых лап $(b)$.
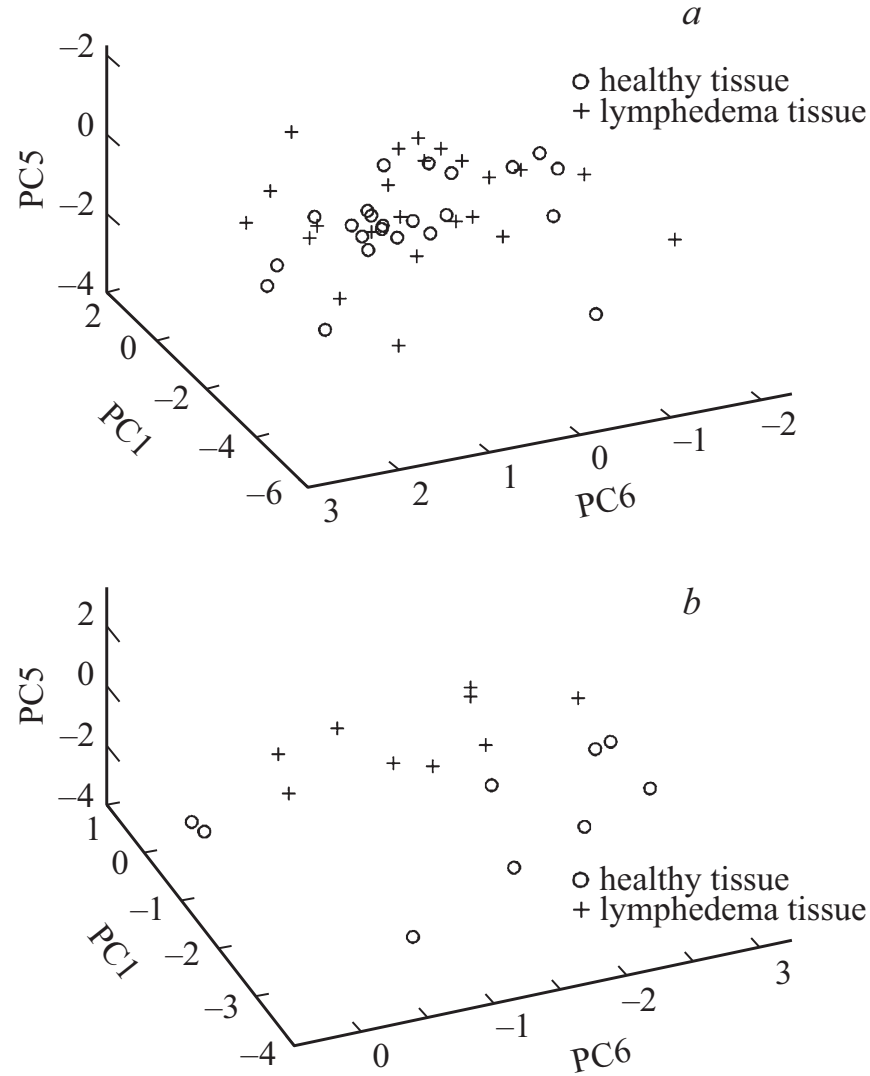

Рис. 9. Проекции $\mathrm{THz}$ спектров поглощения ткани прооперированных и здоровых лап на гиперплоскость 1-й, 5-й и 6-й главных компонент, соответствующих 1-2-й неделям $(a), 3-4-$ й неделям эксперимента $(b)$.

стическая модель диагностики данного заболевания на основе профилей кривых поглощения ткани в области 0.4-1.1 THz с использованием метода главных компонент и метода опорных векторов. При тестировании модель показала достаточно высокие значения средних значений специфичности и чувствительности. Заметные значения среднеквадратичного отклонения данных параметров обусловлены небольшой выборкой на 4-й неделе наблюдения. Однако основные методические результаты работы видны и на имеющемся наборе данных.

Таким образом, предложенные методики могут быть полезны при исследовании морфологических изменений в лимфоматозных конечностях in vivo. 


\section{Финансирование работы}

Исследование выполнено в рамках программы фундаментальных научных исследований государственных академий наук на 2013-2020 годы, направление III.23; а также при финансовой поддержке РФФИ и Администрации Томской области в рамках научного проекта № 1842-703012.

\section{Соблюдение этических стандартов}

Bсе применимые международные, национальные и институционные принципы ухода и использования животных были соблюдены.

\section{Конфликт интересов}

Авторы заявляют, что у них нет конфликта интересов.

\section{Список литературы}

[1] Lee B.B., Bergan J., Rockson S.G. Lymphedema: a concise compendium of theory and practice, London: Springer-Verlag, 2011. 599 p.

[2] Warren A.G., Brorson H., Borud L.J, Slavin S.A. // J. Ann. Plast. Surg. 2007. V. 59. P. 464.

[3] Kinmonth J. // J. Clin. Sci. 1952. V. 11. ? 13.

[4] Sherman A.I., Ter-Pogossian M. // Cancer. 1953. V. 6. N 6. P. 1238.

[5] Cambria R.A., Gloviczki P., Naessens J.M., Waher H.W. // J. Vasc. Surg. 1993. V. 18. P. 775.

[6] Concensus Document of the International Society of Lymphology // Lymphology. 2009. V. 42. N 2. P. 51.

[7] Doh S.J., Yamakawa M., Santosa S.M., Montana M., Guo K., Sauer J.R., Curran N., Han K.-Y., Yu Ch., Ema M., Rosenblatt M.I., Chang J.-H., Azar D.T. // Angeogenesis. 2018. V. 21. N 4. P. 677. doi 10.1007/s10456-018-9629-2

[8] Hadjis N.S., Carr D.H., Banks L., Pflug J.J. // AJR. 1985. V. 144. P. 361.

[9] Bok S.K., Jeon Y., Lee J.A., Ahn S.Y. // Lymphat. Res. Biol. 2018. V. 16. N 1. P. 36. doi 10.1089/1rb.2016.0048

[10] Nightingale K., McAleavey S., Trahey G. // Ultrasound Med. Biol. 2003. V. 29. P. 1715.

[11] Li J., Liu Ch.-H., Schill A., Singh M., Kistenev Yu.V., Larin K.V. A comparison study of optical coherence elastography and laser Michelson vibrometry, Optical Elastography and Tissue Biomechanics III. / Proc. of SPIE. 2009. V. 9710. P. 97101A.

[12] Proulx S.T., Luciani P., Dieterich L.C., Karaman S., Leroux J.C., Detmar M. // J Control Release. 2013. V. 172. N 2. P. 550. doi 10.1016/j.jconrel.2013.04.027

[13] Smolyanskaya O.A., Chernomyrdin N.V., Konovko A.A., Zaytsev K.I., Ozheredov I.A., Cherkasova O.P., Nazarov M.M., Guillet J.P., Kozlov S.A., Kistenev Y.V. Coutaz J.L. // Progress in Quantum Electronics. 2018. V. 62. P. 1.

[14] Peiponen K.-E., Zeitler A., Kuwata-Gonokami M. Terahertz Spectroscopy and Imaging. Springer Series in Optical Sciences, 2013.

[15] Pickwell-MacPherson E., Vincent P. // Photodiagnosis and Photodynamic Therapy. 2009. V. 6. P. 128.
[16] Philip E., Parrott J., Sun Y., Pickwell-MacPherson E. // J. Molecular Struct. 2011. V. 1006. P. 66.

[17] Markelza A.G., Roitberg A., Heilweil E.J. // Chem. Phys. Lett. 2000. V. 320. P. 42.

[18] Ни B.B., Nus M.C. // Optics Letters. 1995. V. 20. N 16. P. 1716.

[19] Pearce J., Choi H., Mittleman D., White J., Zimdars D. Tray reflection computed tomography, CLEO. Baltimore, MD, USA, IEEE. 2005. V. 47. P. R67. doi 10.1109/CLEO.2005.202388

[20] Zaytsev K.I., Gavdush A.A., Chernomyrdin N.V., Yurchenko S.O. // IEEE Transactions on Terahertz Science and Technology. 2015. V. 5. N 5. P. 817.

[21] Загуменников С.Ю., Ковалев А.Г. Патент RU 2322698.

[22] THz Time-Domain Spectroscopy System (Fast scaning) / Technical description. Ekspla UAB. 2016. P. 37.

[23] Борн М., Вольфб Э. Основы оптики. М.: Наука, 1970. 856 с.

[24] Kistenev Yu.V., Borisov A.V., Kuzmin D.A., Penkova O.V., Kostyukova N.Yu., Karapuzikov A.A. // J. Biomed. Opt. 2017. V. 22. N 1. P. 017002. doi 10.1117/1.JBO.22.1.017002

[24] Kistenev Yu.V., Kuzmin D.A., Vrazhnov D.A., Borisov A.V. // Proceedings of SPIE. The International Society for Optical Engineering. 2016. V. 10035. P. 1003507.

[26] Statnikov A., Aliferis C.F., Hardin D.P. A Gentle Introduction to Support Vector Machines in Biomedicine: Theory and methods. World Scientific, 2011. 200 p. 